Original Research Article

\title{
Hemodynamic effects of contrast media and its adverse effects in Western Rajasthan: an observational study
}

\author{
Akhtar Ali ${ }^{*}$, Rajkumar Rathore ${ }^{1}$, Kirti Chaturvedi $^{2}$, Amreesh Parvez $^{3}$
}

${ }^{1}$ Department of Pharmacology,

${ }^{2}$ Department of Radiology, Dr.

S.N. Medical College, Jodhpur,

Rajasthan, India

${ }^{3}$ Life Sciences and

Biotechnology, South Asian

University, New Delhi, India

Received: 19 February 2019

Revised: 19 March 2019

Accepted: 28 March 2019

*Correspondence to:

Dr. Akhtar Ali,

Email: drakhtar06@gmail.com

Copyright: (C) the author(s), publisher and licensee Medip Academy. This is an openaccess article distributed under the terms of the Creative Commons Attribution NonCommercial License, which permits unrestricted noncommercial use, distribution, and reproduction in any medium, provided the original work is properly cited.

\begin{abstract}
Background: This study was aimed to investigate the hemodynamic effects of CT scan contrast media on pulse rate and blood pressure as well as identify the possible adverse drug reactions occurring after administration of contrast media. Methods: Information of patients such as age, sex, diagnosis, prescribed body part for CT scan, amount of contrast media and route of administration of contrast media were collected. Pulse and blood pressure were measured three times, before administration of iohexol or diatrizoate sodium; after $5 \mathrm{~min}$ and $1 \mathrm{hr}$ administration of iohexol; after $1 \mathrm{hr}$ and $2 \mathrm{hr}$ starting of administration of diatrizoate sodium. ADR occurring after contrast media administration were observed.

Results: Before Iohexol administration, SBP was $126.85 \pm 18.47 \mathrm{mmHg}$, which increased by $129.92 \pm 20.51$ and $128.24 \pm 19.89 \mathrm{mmHg}$ after $5 \mathrm{~min}$. and $1 \mathrm{hr}$ respectively after administration. Whereas before iohexol administration, DBP was $81.28 \pm 11.5 \mathrm{~mm} \mathrm{Hg}$, which was decreased by $80.58 \pm 13.03$ and $78.90 \pm 13.15$ $\mathrm{mmHg}$ after administration. The p-value for PR, pre-iohexol vs $1 \mathrm{hr}$ post-iohexol was highly significant. Before Diatrizoate Sodium administration, SBP was $128.84 \pm 17.64 \mathrm{mmHg}$, that was decreased with $126.23 \pm 17.92$ and $124.15 \pm 17.04$ $\mathrm{mmHg}$ after administration. On the other hand, DBP was $81 \pm 11.99 \mathrm{mmHg}$ which was decreased with $80.23 \pm 11.07$ and $79.84 \pm 11.31 \mathrm{mmHg}$ by Diatrizoate Sodium administration. P-value for SBP, DBP, and PR in various comparison of diatrizoate sodium administration was insignificant as well as total 18 ADRs were recorded post diatrizoate sodium and iohexol administration.

Conclusions: Present study result demonstrates PR was significantly increased by administration of iohexol but not that much due to Diatrizoate Sodium especially after the $1 \mathrm{hr}$ of iohexol administration. Although DBP decreased by both drugs, on the other hand, SBP increased by iohexol and decreased by Diatrizoate Sodium administration which was clinically insignificant. Although headache and giddiness were most common ADRs by both drugs.
\end{abstract}

Keywords: Adverse drug reactions, CT scan, Diatrizoate sodium, Iohexol

\section{INTRODUCTION}

Many advanced diagnostic techniques are used prior to the 90 s, such as radiographic imaging intravascular iodinated contrast agents as the mainstay. In the subsequential years, a marked decrease of abdominal and cardiac contrast procedures is noticed in many referral institutions due to the advent of diagnostic ultrasound. Since the start of the twenty-first century, the use of computed tomography
(CT) and magnetic resonance imaging (MRI) have increased. The increased accessibility, enhanced applications, and minimal invasiveness of these techniques have made them currently a popular diagnostic modality in medical science. Intravascular and extra-vascular contrast medium are used in many of CT scan studies. Over the last few years, particularly with the advent of helical multislice CT machines, there has been a marked increase in diagnostic use of Computed tomography angiography 
(CTA), the study of vascular structures by utilizing contrast agents during the CT examination and multiphase angiography to investigate arterial and venous phases, as well as organ perfusion. There has been a dramatic increase in the use of intravascular and extravascular iodinated contrast agents again, because of the increased research and knowledge about the diagnostic advantages of these techniques. ${ }^{1-3}$ Further, their potential side effects must be kept in mind in routine clinical practice.

There are different types of iodinated contrast agents used in diagnostic imaging, based on their physical and chemical properties. All the first generation agents belong to high-osmolar ionic monomers. There is an increased rate of adverse reactions due to the high osmolality of these agents, so the safer second and third generation agents have replaced them. ${ }^{4}$ The low osmolar, non-ionic monomer second generation iodinated compounds (iopamidol and iohexol) with improved vascular tolerability and fewer side effects are most commonly used. The iodine content of a contrast medium is directly related to its radio-opacity, therefore the successive generations of contrast media have been developed with a goal to maximize the iodine content but minimize the osmolarity of the resulting solution. The safest contrast agents reported till date are the third generation iodinated contrast media (Iodixanol and iotrolan) which are isoosmolar, non-ionic dimers. However, they have limited use in human patients at risk of contrast-induced nephrotoxicity (CIN) and in particular those patients with severe renal insufficiency because of their high costs. ${ }^{5-7}$ Though some other reports have contrast findings and they show no difference between second and third generation contrast agents to induce CIN. ${ }^{8}$

There has been an extensive reporting and investigation of adverse reactions due to iodinated intravenous contrast media. ${ }^{4,8-11}$ The physical and chemical properties can be attributed to their side effects. Side effects can be divided into non-anaphylactoid, anaphylactoid and delayed. Pulmonary edema, cardiac arrhythmias, nausea, seizures, and renal failure are the non-anaphylactoid reactions while Urticaria, laryngeal edema and bronchospasm the anaphylactoid reactions. This is not stimulated by an immunoglobulin E-mediated response and so is not true anaphylaxis and it may also occur during the first exposure to the agent. Although, the treatment is the same as for an anaphylactic reaction. The above reactions appear within 1-3 minutes whereas delayed reactions may occur up to 6 hours after exposure which include fever, pruritis, arthralgia, headache, nausea, andvomiting. ${ }^{4}$

Contrast materials, also called contrast agents or contrast media, are used to improve pictures of the inside of the body produced by x-rays, computed tomography (CT), magnetic resonance (MR) imaging, and ultrasound. Moreover, the radiologist can also distinguish between normal conditions and abnormal conditions using contrast materials. Contrast materials temporarily change the way of X-rays or other imaging tools interact with the body and do not discolor internal organs permanently. When introduced into the body prior to an imaging exam, contrast materials make certain structures or tissues in the body appear different on the images than they would if no contrast material had been administered. ${ }^{12}$ Contrast materials help distinguish or "contrast" selected areas of the body from surrounding tissue. By improving the visibility of specific organs, blood vessels or tissues, contrast materials helping in diagnosis. Route of administration of Contrast materials is oral, rectal or systemic by injecting into a blood vessel (vein or artery) or intrathecaly. ${ }^{13}$

Most iodinated contrast media are administered via vascular, whereas, several of these agents are administered via nonvascular routes during such procedures as gastrointestinal imaging, cystography, sialography, cystography, and hysterosalpingography. ${ }^{14}$ The non-ionic iodinated contrast media is increasing rapidly in the population, although the safety profiles of this contrast media have been recognized as the most important issue. Many studies have been performed to investigate the safety profiles of ionic and non-ionic iodinated contrast media. ${ }^{2-4}$ However, only very few studies of Indian patients have been performed, in which sample sizes are generally small that could not fully reflect the incidence and pattern of adverse drug reactions (ADRs) induced by contrast media in Indian patients. ${ }^{15}$

In this study, authors demonstrate the hemodynamic effects and adverse effects of contrast media in respect to blood pressure and pulse rate.

\section{METHODS}

\section{Study design}

This was an observational, noninterventional, and prospective study conducted with the Association with the Department of Pharmacology and Department of Radiology, Dr. S. N. Medical College, Jodhpur. In this study, we used the contrast media iohexol and diatrizoate sodium. This was a single-centric study conducted at Mahatma Gandhi Hospital Jodhpur, a tertiary care center in western Rajasthan. Contrast media preparation and administration were performed, heart rate and blood pressure monitored.

\section{Study patients}

A total of 75 patients aged between 18 years to 75 years were studied, those referred for contrast CT scan of the various regions(thorax, abdomen, head and CT angiography). Out of 75 patients, 45 were male and remaining 30 were female participants. All 75 participants received iohexol intravenously as a contrast media and out of 75, 26 participants also received oral contrast media (diatrizoate sodium) that was given 2 hours before the iohexol media. 
Participants Age between 18 to 75 years were included in the study, in that pregnant females and bedridden patients were excluded in this study. Written consent was taken from all participants. After taking informed consent, participants were included in the study.

\section{Contrast material administration protocol}

We selected participants in whom iohexol was used as an intravenous contrast media and diatrizoate sodium as an oral contrast media. Contrast media were warmed at $37^{\circ} \mathrm{C}$ temperature before the administration. $80 \mathrm{~mL}$ iohexol were administered intravenously with $4 \mathrm{~mL} / \mathrm{sec}(35 \mathrm{ml}) \mathrm{Via} 18$ to the 20-gauge intravenous catheter. On the other hand, $60 \mathrm{ml}$ diatrizoate sodium were mixed in 2 liters of water for preparation of oral contrast media and allow the participants to drink within $2 \mathrm{hr}$,

\section{Observation and monitoring}

Participants were divided into group A and group B on the basis of participant administrated with iohexol (IV) or both iohexol (IV) and diatrizoate sodium (orally) respectively. Observations and monitoring were based on the basis of these groups. In group A, blood pressure and pulse rate monitored within 5 minutes before the iohexol administration, after 5 minutes and $1 \mathrm{hr}$ of iohexol administration. In group B blood pressure and pulse rate were monitored, before the start of contrast media, 1 and 2 $\mathrm{hr}$ after started of oral contrast media administration then CT scan performed and again BP and pulse rate monitored after $5 \mathrm{~min}$ and $1 \mathrm{hr}$ of Iohexol administration. Adverse drug reaction was monitored during this period and necessary clinical action was done if any reaction was observed.

\section{RESULTS \\ Effect of iohexol on blood pressure and pulse rate}

Before administering of iohexol IV, authors observed systolic blood pressure(SBP), diastolic blood pressure (DBP), and pulse rate (PR) were $126.85 \pm 18.47 \mathrm{~mm} \mathrm{Hg}$, $81.28 \pm 11.50 \mathrm{~mm} \mathrm{Hg}$, and86.12 $\pm 17.12 / \mathrm{min}$ respectively (Table 1). After administration of iohexol IV within $5 \mathrm{~min}$, SBP and PR was increased which were $129.92 \pm 20.51 \mathrm{~mm}$ $\mathrm{Hg}$ and $89.94 \pm 15.28 / \mathrm{min}$. This increased in SBP and PR were also observed after $1 \mathrm{hr}$ showed in Table 1 . Whereas DBP was decreased $(80.58 \pm 13.03 \mathrm{~mm} \mathrm{Hg})$ after the $5 \mathrm{~min}$ and decreased in DBP also observe after $1 \mathrm{hr}$ of administration, shown in Table 1.The observation of pulse rate was highly significant in respect to SBP and DBP after the $1 \mathrm{hr}$ of iohexol administration which was not observed in previous studies (Table 1).

Table 1: Effect of iohexol on blood pressure and pulse rate.

\begin{tabular}{|lllllll|}
\hline Parameters & $\begin{array}{l}\text { Before } \\
(\mathbf{M e a n} \pm \text { SD) }\end{array}$ & $\begin{array}{l}\text { After 5min } \\
(\text { Mean } \pm \text { SD })\end{array}$ & $\begin{array}{l}\text { After 1hr } \\
(\text { Mean } \pm \text { SD })\end{array}$ & $\begin{array}{l}\text { P value } \\
\text { Before vs } \\
\text { After 5 min }\end{array}$ & $\begin{array}{l}\text { After 5min. } \\
\text { vs After 1 hr }\end{array}$ & $\begin{array}{l}\text { Before vs } \\
\text { After 1 hr }\end{array}$ \\
\hline SBP $(\mathrm{mmHg})$ & $126.85 \pm 18.47$ & $129.92 \pm 20.51$ & $128.24 \pm 19.89$ & 0.337 & 0.610 & 0.658 \\
\hline DBP $(\mathrm{mmHg})$ & $81.28 \pm 11.50$ & $80.58 \pm 13.03$ & $78.90 \pm 13.15$ & 0.730 & 0.433 & 0.241 \\
\hline PR Rate/minute & $86.12 \pm 17.12$ & $89.94 \pm 15.28$ & $92.36 \pm 16.02$ & 0.150 & 0.346 & $0.026^{*}$ \\
\hline
\end{tabular}

* represent significant $\mathrm{P}$ value.

Table 2: Effect of Diatrizoate Sodium on blood pressure and pulse rate.

\begin{tabular}{|ll|lllll|}
\hline Parameters & $\begin{array}{l}\text { Before } \\
(\text { Mean } \pm \text { SD) }\end{array}$ & $\begin{array}{l}\text { After 1hr } \\
(\text { Mean } \pm \text { SD) }\end{array}$ & $\begin{array}{l}\text { After 2hrs } \\
(\text { Mean } \pm \text { SD) }\end{array}$ & $\begin{array}{l}\text { P value } \\
\text { Before vs } \\
\text { After 1 hr }\end{array}$ & $\begin{array}{l}\text { Before vs } \\
\text { After 2 hrs }\end{array}$ & $\begin{array}{l}\text { After 1hr } \\
\text { vs } \mathbf{~ h r s ~}\end{array}$ \\
\hline SBP $(\mathrm{mmHg})$ & $128.84 \pm 17.64$ & $126.23 \pm 17.92$ & $124.15 \pm 17.04$ & 0.938 & 0.726 & 0.670 \\
\hline DBP $(\mathrm{mmHg})$ & $81 \pm 11.99$ & $80.23 \pm 11.07$ & $79.84 \pm 11.31$ & 0.811 & 0.722 & 0.901 \\
\hline Pulse Rate/ minute & $83.34 \pm 13.78$ & $85.38 \pm 14.47$ & $85.11 \pm 14.36$ & 0.605 & 0.652 & 0.946 \\
\hline
\end{tabular}

\section{Effects of diatrizoate sodium on blood pressure and pulse rate}

Before administering of Diatrizoate Sodium (orally), authors observed SBP, DBP, and PR which were $128.84 \pm 17.64 \mathrm{~mm} \mathrm{Hg}, \quad 81 \pm 11.99 \mathrm{~mm} \mathrm{Hg}$, and $83.34 \pm 13.78 / \mathrm{min}$ respectively (Table 2). After administration of diatrizoate sodium, SBP and DBP were decreased within $1 \mathrm{hr}$, which were $126.23 \pm 17.92 \mathrm{~mm} \mathrm{Hg}$ and $80.23 \pm 11.07 \mathrm{~mm} \mathrm{Hg}$ respectively, showed in Table 2 . This decreased in SBP and DBP were nearly constant in following $2 \mathrm{hr}$ after administration. On the other hand, PR was increased with $85.34 \pm 14.47 / \mathrm{min}$ and nearly constant in following $2 \mathrm{hr}$ after the administration, showed in Table 2. 


\section{Adverse drug reaction}

A total of 18 (24\%) participants with ADRs were recorded out of 75 participants, among them, $9(18 \%)$ and 5 $(19.23 \%)$ were after administration of IV iohexol and diatrizoate sodium orally respectively, showed in Table 3. $4(15.38 \%)$ ADRs were found after combined use of IV iohexol and diatrizoate sodium (orally).

Another side if we calculate it differently than 13 (17.33\%) participants get ADRs out of 75 with iohexol administration and $9(34.61 \%)$ out of 26 participants got the ADRs. So, the incidence of ADRs due to IV iohexol $(17.33 \%)$ administration was less comparatively oral diatrizoate sodium (34.61\%) administration (Table 3).

Table 3: Adverse drug reaction.

\begin{tabular}{|lll|}
\hline Type of contrast media & Total & ADR \\
\hline IV (iohexol) & $49(65.33 \%)$ & $9(18.37 \%)$ \\
\hline $\begin{array}{l}\text { Oral (diatrizoate sodium) } \\
\text { (before IV) }\end{array}$ & $26(34.67 \%)$ & $5(19.23 \%)$ \\
\hline IV+ oral & $26(34.67 \%)$ & $4(15.38 \%)$ \\
\hline Total & 75 & $18(24 \%)$ \\
\hline
\end{tabular}

\section{Type of adverse drug reaction}

Total 28 ADRs were found in 75 participants. These were headache $(n=11)$, giddiness $(n=8)$, vomiting $(n=2)$, abdominal pain $(\mathrm{n}=2)$, flushing of skin $(\mathrm{n}=2)$, diarrhea $(n=2)$, syncope $(n=1)$. Headache $(39.29 \%)$ was most common ADR. So, in this view headache and giddiness were most common ADRs (Table 4).

Table 4: Types of adverse drug reaction.

\begin{tabular}{|lll|}
\hline Type of ADR & Total & Percentage (\%) \\
\hline Headache & 11 & 39.29 \\
\hline Giddiness & 8 & 28.57 \\
\hline Vomiting & 2 & 7.14 \\
\hline Abdomen pain & 2 & 7.14 \\
\hline Syncope & 1 & 3.57 \\
\hline Flushing of skin & 2 & 7.14 \\
\hline Diarrhea & 2 & 7.14 \\
\hline Total & 28 & 100 \\
\hline
\end{tabular}

\section{Type of adverse drug reaction by using different contrast} media

Total 28 ADRs were found in 75 participants. Among them, 14 ADRs occur after administration of Diatrizoate Sodium (orally). Out of these headache $(n=2)$, giddiness $(n=6)$, vomiting $(n=2)$, abdominal pain $(n=2)$ and diarrhea $(n=2)$, showed in Table 5. Giddiness was most common ADR caused by Diatrizoate Sodium (23\%). 14 ADRs occur after administration of iohexol (IV) out of this headache $(n=9)$, giddiness $(n=2)$, flushing of skin $(n=2)$ and syncope $(n=1)$. So, in the above view headache $(12 \%)$ was most common ADRs which occurred after administration of IV iohexol while giddiness $(23.08 \%)$ was most common ADRs due to diatrizoate sodium (orally) (Table 5).

Table 5: Adverse drug reaction by using different contrast media.

\begin{tabular}{|ll|l|}
\hline Type of ADR & $\begin{array}{l}\text { ORAL (diatrizoate } \\
\text { sodium) }\end{array}$ & IV (iohexol) \\
\hline Headache & $2(7.69 \%)$ & $9(12 \%)$ \\
\hline Giddiness & $6(23.08 \%)$ & $2(2.67 \%)$ \\
\hline Vomiting & $2(7.69 \%)$ & 0 \\
\hline Abdomen pain & $2(7.69 \%)$ & 0 \\
\hline Syncope & 0 & $1(1.335 \%)$ \\
\hline Diarrhea & $2(7.69 \%)$ & 0 \\
\hline Flushing of skin & 0 & $2(2.67 \%)$ \\
\hline Total & $14(53.85 \%)$ & $14(18.67 \%)$ \\
\hline
\end{tabular}

\section{DISCUSSION}

The aim of the study was to evaluate the hemodynamic effects of CT scan contrast media on pulse rate and blood pressure as well as identify the possible adverse drug reactions occurring after administration of contrast media in patients visiting Radiology Department for contrast CT scan for that we observed 75 patients.

In present study post-diatrizoate sodium administration, SBP and DBP were decreased which was clinically insignificant, on the other hand, PR was increased after diatrizoate sodium administration, but it was clinically insignificant. While Hirschfeld et al, reported in left ventriculography, diatrizoate caused a significant increase in left ventricular end diastolic pressure, cardiac output, and corrected QT interval while causing a greater decrease in arterial pressure comparing to ioversol or iopamidol, following left coronary arteriography, diatrizoate caused a significant decrease in heart rate. ${ }^{16}$

Present study revealed the post iohexol administration SBP was increased but DBP was decreased, although this was clinically insignificant. While Ning et al, show that ferumoxytol is effective as an MR contrast agent and there are small but clinically insignificant fall in SBP and DBP post-contrastinjection. ${ }^{17}$ Hayashi et al, found Intravenous Gadoxetate disodium (a weight-based dose) does not cause any changes in $\mathrm{SpO}_{2}$ and heart rate. ${ }^{18}$

Present study showed, that pulse rate increase after $1 \mathrm{hr}$ of post iohexol administration was highly significant but increase in PR after 5 min of iohexol administration was insignificant. Which is not according to James et al, study, in that study they demonstrated that there were no clinically significant changes in heart rate, new rhythms or cardiac waveform morphology or AV conduction, either by IV or non-cardiac intraarterial injection of iosimenol. There are no such significant differences recorded between groups receiving iodixanol and those receiving Iosimenol. ${ }^{19}$ 
Present study shows that incidence of ADRs due to IV iohexol was $17.33 \%$ and diatrizoate sodium was $34.61 \%$ which was quite high. A mild headache and giddiness were most common ADRs due to iohexol and diatrizoate sodium administration, among this mild headache (12\%) were most common ADRs which occurred due to IV Iohexol while giddiness $(23.08 \%)$ was most common ADRs due to diatrizoate sodium (orally). Which was not according to Subathra et al, they demonstrated in their study, most common adverse reactions to contrast are nausea, vomiting, and rashes. Most of the reactions occur immediately after administration of contrast and mostly are mild to moderate in nature. ${ }^{20}$ While Egbert et al, found in their study that delayed adverse reactions to contrast media are not rare but often not recognized as being linked with to contrast administration and maybe occasionally falsly attributed to other drugs. These side effects are sometimes problematic because the patient is usually without medical supervision. $^{21}$

\section{ACKNOWLEDGEMENTS}

Authors express thanks to Dr. Parul Chaturvedy, Senior Resident, Department of Microbiology, S.M.S. Medical College, Jaipur (Rajasthan) for her technical assistance.

Funding: No funding sources Conflict of interest: None declared

Ethical approval: The study was approved by the Institutional Ethics Committee

\section{REFERENCES}

1. Frush DP. Imaging of pediatric mediastinal masses. Ann Acad Med Singapore. 2003;32:525-35.

2. Kopka L, Rodenwaldt J, Fischer U, Mueller DW, Oestmann JW, Grabbe E. Dual-phase helical CT of the liver: Effects of bolus tracking and different volumes of contrast material. Radiol. 1996;201:321-6.

3. Mehnert F, Pereira PL, Trübenbach J, Kopp AF, Claussen CD. Biphasic spiral CT of the liver: Autonomic bolus tracking or time delay? Eur Radiol. 2001;11:427-31.

4. Widmark JM. Imaging-related medications: A class overview. Pro Baylor Med Cen Pharmacol Notes: Garland. 2007;20:408-17.

5. Manual on contrast media. 2008. Available at: www.acr.org/Secondary Main Menu Categories / quality_safety/contrast_manual.aspx.

6. Nguyen SA, Suranyi P, Ravenel JG, Randall PK, Romano PB, Strom KA, et al. Iso-osmolality versus low-osmolality iodinated contrast medium at intravenous contrast-enhanced CT: effect on kidney function. Radiol. 2008;248(1):97-105.

7. Hsieh YC, Liu TJ, Liang KW, Her HY, Lin WW, Wang KY, et al. Iso-osmolar ccontrast medium better preserves short- and long-term renal function after cardiovascular catheterizations in patients with severe baseline renal insufficiency. Int $\mathrm{J}$ Cardiol. 2006;111:182-4.
8. Barrett BJ, Katzberg RW, Thomsen HS, Chen N, Sahani D, Soulez G, et al. Contrast-induced nephropathy in patients with chronic kidney disease undergoing computed tomography: A double-blind comparison of iodixanol and iopamidol. Invest Radiol. 2006;41:815-21.

9. Lindholt JS. Radiocontrast induced nephropathy. Eur J Vasc Endovasc Surg. 2003 Apr 1;25(4):296-304.

10. Romano G, Briguori C, Quintavalle C, Zanca C, Rivera NV, Colombo A, et al. Contrast agents and renal cell apoptosis. Eur Heart. 2008 May 8;29(20):2569-76.

11. Schild HH, Kuhl CK, Hübner-Steiner U, Böhm I, Speck U. Adverse events after unenhanced and monomeric and dimeric contrast-enhanced CT: a prospective randomized controlled trial. Radiol. 2006 Jul;240(1):56-64.

12. Wong PC, Li Z, Guo J, Zhang A. Pathophysiology of contrast-induced nephropathy. Int J Cardiol. 2012 Jul 12;158(2):186-92.

13. Katayama H, Yamaguchi K, Kozuka T, Takashima T, Seez P, Matsuura K. Adverse reactions to ionic and nonionic contrast media. A report from the Japanese Committee on the Safety of Contrast Media. Radiolo. 1990 Jun;175(3):621-8.

14. Kopp AF, Mortele KJ, Cho YD, Palkowitsch P, Bettmann MA, Claussen CD. Prevalence of acute reactions to iopromide: postmarketing surveillance study of 74,717 patients. Acta Radiol. 2008;49:90211.

15. Mortelé KJ, Oliva MR, Ondategui S, Ros PR, Silverman SG. Universal use of nonionic iodinated contrast medium for CT: evaluation of safety in a large urban teaching hospital. Am J Roentgenol. 2005 Jan;184(1):31-4.

16. Hirshfeld JJ, Wieland JE, Davis CA, Giles BD, Passione DA, Ray MB, et al. Hemodynamic and electrocardiographic effects of ioversol during cardiac angiography. Comparison with iopamidol and diatrizoate. Invest Radiol. 1989;24(2):138-44.

17. Ning $P$, Zucker EJ, Wong $P$, Vasanawala SS. Hemodynamic safety and efficacy of ferumoxytol as an intravenous contrast agents in pediatric patients and young adults. Magnetic Resonance Imaging. 20161;34(2):152-8.

18. Hayashi T, Saitoh S, Tsuji Y, Takahashi J, Tagaya N, Hiramoto M, et al. Influence of Gadoxetate Disodium on Oxygen Saturation and Heart Rate during Dynamic Contrast-enhanced MR Imaging. Radiol. 2015;276(3):756-65.

19. James J. Zhang, MD, Joel Morganroth, MD, Barry Hogstrom, MD. Electrocardiographic Response to Intravenous and Intraarterial Injection of Iosimenol (A New, Iodinated, Non-Ionic, Iso-Osmolar Contrast Medium). J Invasive Cardiol. 2016; 25:11.

20. Subathra A, Sandhiya S, Kesavan R. An analysis of adverse drug reactions to radiographic contrast media reported during a 3 year period in a tertiary care hospital in south India. Indian J Physiol Pharmacol. 2014;58(1):45-50. 
21. Egbert RE, De Cecco CN, Schoepf UJ, McQuiston AD, Meinel FG, Katzberg RW. Delayed adverse reactions to the parenteral administration of iodinated contrast media. Am J Roentgenol. 2014;203(6):116370 .
Cite this article as: Ali A, Rathore R, Chaturvedi K, Parvez A. Hemodynamic effects of contrast media and its adverse effects in Western Rajasthan: an observational study. Int J Basic Clin Pharmacol 2019;8:967-72. 